\title{
Diagnose foliar em mudas de pinhão-manso (Jatropha Curcas L.) produzidas com biossólido
}

\author{
Reginaldo de Camargo', Alirio C. D. Maldonado', Polianna A. S. Dias', \\ Monique F. Souza ${ }^{1} \&$ Marcelo S. França ${ }^{1}$
}

\begin{abstract}
RESUMO
O uso do biossólido na agricultura tem-se mostrado a melhor alternativa ambiental e econômica para o destino do lodo de esgoto. O objetivo deste trabalho foi avaliar o potencial nutricional do biossólido para produção de mudas de pinhão-manso em tubetes. O experimento foi realizado em casa de vegetação tendo, como substrato, esterco bovino, vermiculita e biossólido. O delineamento experimental foi o de blocos casualizados com três repetições em esquema fatorial $5 \times 2$, correspondendo às concentrações de biossólido no substrato $(0,10,20,30$ e 40\%) e ao tratamento ou não das sementes de pinhão-manso com fungicida. Aos 60 dias foi realizada análise foliar. Relativo às concentrações de biossólido verificou-se efeito significativo para os macronutrientes $\mathrm{N}, \mathrm{P}, \mathrm{Ca}, \mathrm{Mg}$ e $\mathrm{S}$ e micronutrientes $\mathrm{B}, \mathrm{Cu}, \mathrm{Mn}$ e $\mathrm{Zn}$. O tratamento de sementes teve efeito significativo para o $\mathrm{Zn}$. As folhas apresentaram concentração de macronutrientes com a seguinte ordem: $\mathrm{N}>\mathrm{K}>\mathrm{Mg}>\mathrm{Ca}>\mathrm{P}>\mathrm{S}$. O acúmulo de micronutrientes apresentou a seguinte ordem: Fé $>M n>Z n>B>C u$. Há grande contribuição do biossólido nos teores de nitrogênio, enxofre e micronutrientes foliares, em plantas de pinhão-manso.
\end{abstract}

Palavras-chave: nutrição mineral de plantas, lodo de esgoto, reciclagem de resíduos orgânicos

\section{Foliar analysis of jatropha (Jatropha curcas L.) seedlings grown with biosolid}

\begin{abstract}
The use of biosolids in agriculture has proven to be the best alternative for the environmental and economic destination of sewage sludge. The objective of this study was to evaluate the nutritional potential of biosolids to produce jatropha seedlings in polytube. The experiment was conducted in a greenhouse using as substrate manure, biosolids and vermiculite. The experimental design was in randomized block with three replications in a $5 \times 2$ factorial, corresponding to the substrate concentrations in sewage sludge $(0,10,20,30$ and $40 \%)$, and the treatment or not of the seeds of jatropha with fungicide. At 60 days, leaf analysis was performed. Regarding the biosolids concentrations, significant effect was verified for the macronutrients $\mathrm{N}, \mathrm{P}, \mathrm{Ca}, \mathrm{Mg}$ and $\mathrm{S}$, and for the micronutrients $\mathrm{B}, \mathrm{Cu}, \mathrm{Mn}$ and $\mathrm{Zn}$. The seed treatment had a significant effect for $\mathrm{Zn}$. Leaves showed concentration of macronutrients in the following order: $\mathrm{N}>\mathrm{K}>\mathrm{Mg}>\mathrm{Ca}>\mathrm{P}>\mathrm{S}$. The accumulation of micronutrients presented the following order: Fe $>\mathrm{Mn}>\mathrm{Zn}>\mathrm{B}>\mathrm{Cu}$. There is a great contribution of biosolids for the contents of nitrogen, sulfur and micronutrients in leaves of jatropha plants.
\end{abstract}

Key words: mineral nutrition of plants, sewage sludge, recycling organic waste 


\section{INTRODUÇÃO}

Entre as diversas alternativas para a disposição final do lodo de esgoto, aquela para fins agrícolas e florestais apresenta-se como uma das mais convenientes pois como o lodo é rico em matéria orgânica e em nutrientes para as plantas, recomenda-se sua aplicação como condicionador de solo e/ou fertilizante.

O lodo de esgoto é um subproduto do esgoto coletado nas residências e tratado nas estações de tratamento de esgoto (ETE). Segundo pesquisa do censo realizada pelo IBGE em 2008, houve uma melhora no índice referente ao esgoto coletado em 2000 quando 33,5\% das 44,7 milhões de residências brasileiras contavam com o serviço. Em 2008 o índice foi de $44 \%$ dos 57,7 milhões de domicílios. O crescimento populacional possibilitou a transferência de quantidades consideráveis de nutrientes dos solos agrícolas para os resíduos urbanos. Neste processo os compostos presentes em alimentos são despejados nos esgotos depois de utilizados no metabolismo humano. Desta forma, quanto mais investimentos houver em saneamento básico para a coleta e tratamento de esgoto, a geração de lodo será maior. Como a tendência é ocorrer aumento na quantidade de lodo é necessário um manejo adequado do seu uso e destino final. $\mathrm{O}$ Conselho Nacional do Meio Ambiente aprovou a Resolução n. 375, de 29 de agosto de 2006 (CONAMA, 2006) que definiu critérios e procedimentos para o uso agrícola de lodos de esgoto gerados em estações de tratamento de esgoto sanitário e seus produtos derivados. No entanto, para que a reciclagem agrícola ocorra de forma segura e sustentável, o lodo de esgoto deve ser tratado e transformado em um biossólido, termo que especifica características mínimas de qualidade necessárias para seu uso, tais como: potencial agronômico, substâncias tóxicas, indicadores bacteriológicos, agentes patogênicos e estabilidade.

A utilização do biossólido na agricultura como adubo orgânico é vista, atualmente, como a alternativa mais promissora para disposição final deste resíduo. Em experiências realizadas por Campos \& Alves (2008) observou-se, para a cultura do eucalipto, que o lodo apresenta potencial para substituir fertilizantes minerais. Faustino et al. (2005), comprovaram a viabilidade do lodo de esgoto como componente do substrato para produção de mudas de Senna siamea Lam e concluíram que o uso de lodo de esgoto como componente de substratos para produção de mudas pode ser uma alternativa viável para sua disposição final e constitui uma ferramenta a ser utilizada pelas prefeituras na produção de mudas para arborização urbana e recuperação de áreas degradadas.

Outros aspectos positivos são os benefícios como alterações na fertilidade do solo (Colodro \& Espíndola, 2006) e nas suas propriedades físicas (Melo et al., 2004). Do ponto de vista agronômico o biossólido apresenta, em sua constituição, quantidades significativas de nutrientes ao desenvolvimento das plantas, podendo ser uma excelente alternativa, junto com o pinhão-manso, para a recuperação de áreas degradadas (Trannin et al., 2005). Neste contexto esta espécie vem sendo implantada com sucesso, visando ao controle de erosão, à contenção de encostas e dunas e, ao longo de canais, rodovias, ferrovias, e como cerca viva em divisões internas ou limites de propriedades rurais (Saturnino et al., 2005 ). O pinhãomanso (Jatropha curcas L.) é uma planta oleaginosa de alto potencial produtivo e bem adaptado ao semiárido, apontado como importante alternativa para fornecimento de óleo para fabricação de biodiesel (Arruda et al., 2004). Trata-se de uma planta originária da América Central, mas que se encontra vegetando espontaneamente em diversas regiões do Brasil (Lima et al., 2011a). O País possui grandes áreas agricultáveis ainda não exploradas e clima favorável, com diversas alternativas de espécies potencialmente produtoras de óleo. A espécie Jatropha curcas L. pode ser considerada uma das mais importantes alternativas energéticas para a região do cerrado.

O objetivo deste trabalho foi avaliar o potencial do biossólido como fonte de matéria orgânica e de nutrientes para a produção de mudas de pinhão-manso.

\section{Material e Métodos}

$\mathrm{O}$ experimento foi realizado em casa de vegetação no Campus Umuarama do Instituto de Ciências Agrárias (ICIAG) na Universidade Federal de Uberlândia (UFU) localizada no município de Uberlândia, MG. O biossólido foi obtido por meio do tratamento térmico do lodo de esgoto proveniente da Estação de Tratamento de Esgoto Aclimação do DMAE - Departamento de Água e Esgoto, localizado no município de Uberlândia, MG, conforme metodologia proposta por Maldonado (2004). A Tabela 1 apresenta o resultado da análise química e física do lodo seco utilizado neste experimento.

Tabela 1. Teores de elementos verificados na análise química e física do biossólido

\begin{tabular}{|c|c|c|}
\hline Determinações & $\begin{array}{c}\text { Umidade } \\
\text { natural }\end{array}$ & $\begin{array}{c}\text { Base seca } \\
\left(110^{\circ} \mathrm{c}\right)\end{array}$ \\
\hline $\mathrm{pH}$ em $\mathrm{CaCl}_{2}$ 0,01M & 6,0 & - \\
\hline Densidade & $1,1 \mathrm{~g} \mathrm{~cm}^{-3}$ & - \\
\hline Umidade perdida a $60-65^{\circ} \mathrm{C}$ & $2,0 \%$ & - \\
\hline Umidade perdida a $65-110^{\circ} \mathrm{C}$ & $1,2 \%$ & - \\
\hline Umidade total & $3,2 \%$ & - \\
\hline Inertes & - & - \\
\hline Matéria orgânica total (combustão) & $55,0 \%$ & $57,1 \%$ \\
\hline Matéria orgânica compostável & $40,7 \%$ & $42,2 \%$ \\
\hline Matéria orgânica não compostável & $14,4 \%$ & $15,0 \%$ \\
\hline Carbono total (orgânico e mineral) & $30,5 \%$ & $31,7 \%$ \\
\hline Carbono total orgânico & $22,6 \%$ & $23,4 \%$ \\
\hline Resíduo mineral total & $36,4 \%$ & $42,9 \%$ \\
\hline Resíduo mineral insolúvel & $14,0 \%$ & $14,6 \%$ \\
\hline Resíduo mineral solúvel & $27,4 \%$ & $28,4 \%$ \\
\hline Nitrogênio total & $4,0 \%$ & $4,1 \%$ \\
\hline Fósforo $\left(\mathrm{P}_{2} \mathrm{O}_{5}\right)$ total & $2,1 \%$ & $2,3 \%$ \\
\hline Potássio $\left(\mathrm{K}_{2} \mathrm{O}\right)$ total & $4,0 \%$ & $4,1 \%$ \\
\hline Cálcio total & $1,0 \%$ & $1,1 \%$ \\
\hline Magnésio total & $0,1 \%$ & $0,1 \%$ \\
\hline Enxofre total & $0,4 \%$ & $0,5 \%$ \\
\hline Relação C/N (C total e N total) & $7 / 1$ & $7 / 1$ \\
\hline Relação C/N (C orgânico e N total) & $6 / 1$ & $6 / 1$ \\
\hline Cobre total & $1104 \mathrm{mg} \mathrm{kg}^{-1}$ & $1552 \mathrm{mg} \mathrm{kg}^{-1}$ \\
\hline Manganês total & $144 \mathrm{mg} \mathrm{kg}^{-1}$ & $150 \mathrm{mg} \mathrm{kg}^{-1}$ \\
\hline Zinco total & $1026 \mathrm{mg} \mathrm{kg}^{-1}$ & $1064 \mathrm{mg} \mathrm{kg}^{-1}$ \\
\hline Ferro total & $24824 \mathrm{mg} \mathrm{kg}^{-1}$ & $25758 \mathrm{mg} \mathrm{kg}^{-1}$ \\
\hline Boro total & $25 \mathrm{mg} \mathrm{kg}^{-1}$ & $26 \mathrm{mg} \mathrm{kg}^{-1}$ \\
\hline Sódio total & $687 \mathrm{mg} \mathrm{kg}^{-1}$ & $715 \mathrm{mg} \mathrm{kg}^{-1}$ \\
\hline
\end{tabular}

Fonte: Maldonado (2004)

O delineamento experimental utilizado foi o de blocos casualizados, com 3 repetições em esquema fatorial $5 \mathrm{x}$ 
2 correspondendo, respectivamente, às concentrações de biossólido e ao tratamento ou não das sementes de pinhãomanso com fungicida Moncerem ${ }^{\circledR} \mathrm{PM}$ na dosagem de $1,50 \mathrm{~g} \mathrm{~kg}^{-1}$ de sementes. Cada parcela foi representada por 10 tubetes. As sementes foram colhidas em janeiro de 2009 e fornecidas pela COVAL (Cooperativa Agropecuária do Vale da Alimentação Ltda.), do município de Santa Vitória, MG.

Foram avaliados os seguintes substratos: $40 \%$ esterco bovino $+60 \%$ vermiculita, $10 \%$ de biossólido $+40 \%$ esterco bovino $+50 \%$ vermiculita, $20 \%$ de biossólido $+40 \%$ esterco bovino $+40 \%$ vermiculita, $30 \%$ de biossólido $+40 \%$ esterco bovino $+30 \%$ vermiculita, $40 \%$ de biossólido $+40 \%$ esterco bovino $+20 \%$ vermiculita . Foi utilizada vermiculita de granulação ultrafina. A adubação de plantio foi comum a todas as combinações de substratos com $5 \mathrm{~kg} \mathrm{~m}^{-3}$ de superfosfato simples, $1 \mathrm{~kg} \mathrm{~m}^{-3}$ de cloreto de potássio e $2 \mathrm{~kg} \mathrm{~m}^{-3}$ de calcário. Para a adubação de cobertura foi utilizada uma solução de ureia $\left(1,50 \mathrm{~g} \mathrm{~L}^{-1}\right)$, a qual foi aplicada com um regador, no volume de $1 \mathrm{~L} \mathrm{~m}^{-2}$ aos 20,35 e 50 dias após o semeio. Após cada adubação de cobertura as mudas foram irrigadas para lavagem do excesso de solução acumulada nas folhas a fim de evitar a queimadura das mesmas. A duração do experimento foi de 60 dias, contados a partir de 12 de março de 2009. Foram utilizados tubetes de $120 \mathrm{~mL}$ para a semeadura sendo semeadas duas sementes a uma profundidade de $1,5 \mathrm{~cm}$. Após 14 dias foi realizado o desbaste mantendo-se apenas uma plântula por tubete. A irrigação foi feita três vezes ao dia sendo a primeira rega pela manhã, a segunda no início da tarde e a última no fim da tarde. Cronometrava-se o tempo necessário para que uma proveta fosse cheia até a marca de $1 \mathrm{~L}$ e a partir do tempo marcado cada grade era irrigada com $1 \mathrm{~L}$ de água. A água foi distribuída em movimento de ziguezague para que todos os tubetes recebessem água uniformemente.

Aos 60 dias sacos de papel contendo as folhas das plantas foram colocados em estufa de circulação de ar forçado, mantendo a temperatura a $60{ }^{\circ} \mathrm{C}$, até atingir a massa seca constante, o que foi verificado após $72 \mathrm{~h}$ aproximadamente. Os sacos de papel foram retirados da estufa e a matéria seca pesada em balança com precisão de duas casas decimais. A análise foliar para determinação dos teores de macro e micronutrientes foi realizada no Laboratório de Análises de Solos e Calcário da UFU utilizando-se a digestão nitroperclórica. Os dados obtidos foram submetidos à análise estatística efetuando-se análise de regressão para as concentrações de biossólido e teste de $\mathrm{F}$, a nível de 0,05 de significância para o fator tratamento das sementes.

\section{Resultados e Discussão}

As folhas de pinhão-manso apresentaram teores de macronutrientes de acordo com a seguinte ordem: $\mathrm{N}>\mathrm{K}>$ $\mathrm{Mg}>\mathrm{Ca}>\mathrm{P}>\mathrm{S}$ aos sessenta dias (Tabela 2). Exceto para os resultados de $\mathrm{Ca}$ e $\mathrm{Mg}$, os teores de macronutrientes obtidos estão dentro dos valores de referência para interpretação dos resultados de análise de tecidos da CFSEMG (1999) para a mamoneira, espécie da mesma família. Laviola \& Dias (2008) observaram que o teor de $\mathrm{Ca}$ foi inferior apenas ao $\mathrm{N}$ dentre os macronutrientes, com teores de $\mathrm{Ca}, \mathrm{K}, \mathrm{Mg}$ e $\mathrm{S}$ superiores aos observados no presente trabalho. Dentre outros fatores variações no acúmulo foliar de nutrientes podem estar relacionadas ao estádio de desenvolvimento da planta e das folhas, à posição da folha no ramo, ao tipo de ramo e à época de coleta; assim, o fato de Laviola \& Dias (2008) terem realizado a amostragem de folhas em plantas adultas em seu trabalho, isto pode justificar as diferenças dos resultados em relação à presente pesquisa. Lima et al. (2011b) concluíram que as folhas de pinhão-manso dos $2^{\circ}$ e $3^{\circ}$ nós no sentido ápice para a base de ramos secundários, são as mais adequadas para análise foliar de $\mathrm{N}, \mathrm{P}, \mathrm{k}, \mathrm{S}, \mathrm{Cu}, \mathrm{Fe}, \mathrm{Mn}$ e $\mathrm{Zn}$ visto que apresentam valores médios mais estáveis quando comparadas a outras posições estudadas; esses autores determinaram, ainda, que folhas de $5^{\circ}$ e $10^{\circ}$ nós são mais apropriadas para avaliação de Ca e $\mathrm{Mg}$ e que o estádio fenológico do ramo não influencia os teores de nutrientes, exceto de $\mathrm{Cu}$ e Fe.

Tabela 2. Valores médios para macronutrientes nas folhas de pinhão-manso em função das doses de biossólido

\begin{tabular}{ccccccc}
\hline Doses de & \multicolumn{6}{c}{ Macronutrientes (g kg-1 $)$} \\
\cline { 2 - 7 } biossólido (\%) & $\mathbf{N}$ & $\mathbf{P}$ & $\mathbf{K}$ & $\mathbf{C a}$ & $\mathbf{M g}$ & $\mathbf{S}$ \\
$\mathbf{0}$ & 21,58 & 4,32 & 28,50 & 8,22 & 12,52 & 2,13 \\
10,00 & 34,53 & 3,35 & 27,33 & 5,73 & 10,27 & 3,07 \\
20,00 & 40,02 & 2,48 & 28,16 & 5,22 & 8,00 & 3,00 \\
30,00 & 38,38 & 2,63 & 28,75 & 5,85 & 7,47 & 3,60 \\
40,00 & 48,07 & 2,47 & 27,92 & 5,10 & 6,25 & 3,00 \\
\hline Media & 36,52 & 3,05 & 28,13 & 6,02 & 9,00 & 3,00 \\
\hline
\end{tabular}

Verifica-se que a adição do biossólido em diferentes proporções ao substrato influenciou significativamente o acúmulo de nutrientes, exceto para o potássio, apesar deste nutriente se fazer presente com $4,1 \%$ na composição do biossólido utilizado, igualando-se ao nitrogênio. Na composição de $40 \%$ do substrato com biossólido o teor de nitrogênio foliar passou de 21,58 $\mathrm{g} \mathrm{kg}^{-1}$ (testemunha) para $48,07 \mathrm{~g} \mathrm{~kg}^{-1}$, demonstrando que na formação de mudas de pinhão-manso o biossólido apresenta potencial como fonte deste elemento.

Na Figura 1 observa-se que a elevação de 1\% de biossólido no substrato reflete num aumento de $0,56 \mathrm{~g}$ no teor de $\mathrm{N}$ nas folhas do pinhão-manso. O nitrogênio influencia o tamanho final das folhas fazendo com que seja um dos fatores determinantes da taxa de acúmulo de biomassa.

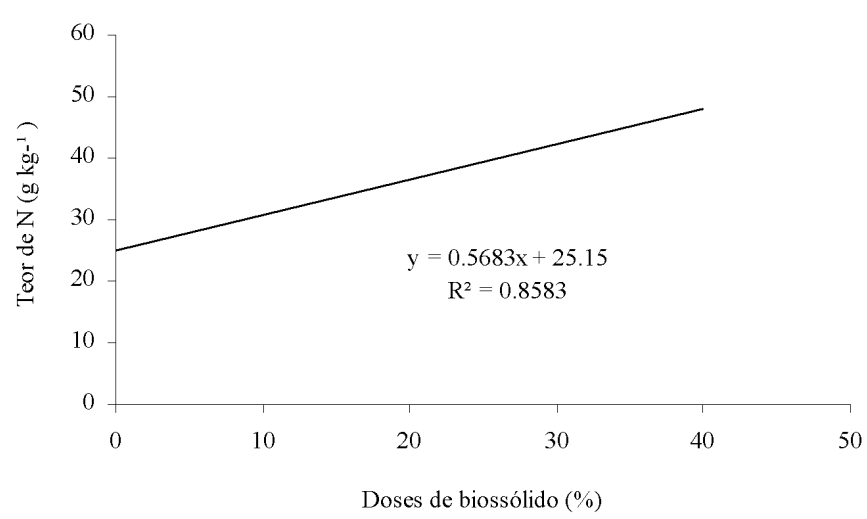

Figura 1. Teor de $\mathrm{N}$ em folhas de pinhão-manso em função de doses de biossólido aos 60 dias após a semeadura 
Tabela 3. Resumo da análise de variância para teores de macronutrientes ( $\mathrm{kg}^{-1}$ de massa seca) em folhas de pinhãomanso em função de diferentes doses de biossólido (D) e tratamento de sementes (T)

\begin{tabular}{|c|c|c|c|c|c|c|c|}
\hline \multirow{2}{*}{ FV } & \multirow{2}{*}{ GL } & \multicolumn{6}{|c|}{ Quadrado médio macronutrientes } \\
\hline & & $\mathbf{N}$ & $\mathbf{P}$ & K & $\mathrm{Ca}$ & $\mathrm{Mg}$ & $\mathbf{S}$ \\
\hline Doses (D) & 4 & $564,11^{*}$ & 3,794 ** & 1,80ns & $9,64^{* \star}$ & $37,25^{\star *}$ & $1,27^{\star *}$ \\
\hline Trat. de semente $(\mathrm{T})$ & 1 & $1,98 \mathrm{~ns}$ & $0,057 \mathrm{~ns}$ & $61,63 \mathrm{~ns}$ & $0,363 n s$ & $0,53 \mathrm{~ns}$ & $0,24 \mathrm{~ns}$ \\
\hline $\mathrm{D} \times \mathrm{T}$ & 4 & $153,43 \mathrm{~ns}$ & $0,021 \mathrm{~ns}$ & $22,53 \mathrm{~ns}$ & $0,49 \mathrm{~ns}$ & $0,30 \mathrm{~ns}$ & $0,305^{\star}$ \\
\hline Bloco & 2 & 1,83 & 0,873 & 50,31 & 0,004 & 0,69 & 0,71 \\
\hline Erro & 18 & 97,05 & 4,46 & 16,19 & 0,63 & 1,00 & 0,09 \\
\hline CV\% & & 26,98 & 16,32 & 14,30 & 13,23 & 11,24 & 10,06 \\
\hline
\end{tabular}

ns não significativo a nível de 0,05 * significativo a nível de 0,05 pelo teste $\mathrm{F}$; ${ }^{* \star}$ significativo a nível de 0,01 pelo teste de $\mathrm{F}$

Backes et al. (2009) obtiveram em mamoneira, aos cinquenta dias após a emergência, elevações expressivas no teor foliar de N (38,7\%), K (50,0\%), Mg (66,0\%) e S (19,0\%) e dos micronutrientes $\mathrm{Cu}(48,9 \%), \mathrm{Fe}(40,6 \%), \mathrm{Mn}(859,7 \%)$ e Zn (314\%) em função da adição de doses de lodo de esgoto no plantio entre 0 e $32 \mathrm{t} \mathrm{ha}^{-1}$. Gomes et al. (2007) verificaram, analisando a produtividade e a composição mineral de plantas de milho em solo com lodo de esgoto, incremento no teor foliar de $\mathrm{N}$ superior a $20 \%$; todavia, sem conseguir suprir a demanda nutricional da planta.

Um acréscimo no suprimento de $\mathrm{N}$ estimula o crescimento, atrasa a senescência e muda a morfologia das plantas; além disto, o aumento nos níveis de adubação nitrogenada causa crescimento significativo no conteúdo de clorofila das folhas (Fernandez et al., 1994 ). Laviola \& Dias (2008) citam que o $\mathrm{N}$ foi o nutriente mais requerido para a formação de folhas, tal como para suprir a demanda metabólica dos frutos de pinhãomanso. Segundo Kerbauy (2008) a demanda de N varia com a espécie e o teor com a parte da planta analisada e, para um crescimento adequado, a concentração está na faixa de 20 a 50 $\mathrm{g} \mathrm{kg}^{-1}$ de matéria seca da planta.

Para o enxofre (Tabela 3) observa-se que houve efeito significativo na interação entre os fatores estudados. Na Figura 2 pode-se notar a interação significativa no desdobramento das doses de biossólido no tratamento da semente sendo que para a semente não tratada ocorre um efeito quadrático em comparação com a semente tratada, o teor de enxofre absorvido é maior e com coeficiente de regressão linear igual a 0,83 . Pelo modelo de ajuste da semente não tratada a partir de $23 \%$ da participação do biossólido na composição do substrato, ocorre decréscimo da dosagem de $\mathrm{S}$ nas folhas e o maior teor de $\mathrm{S}$ absorvido é $3,20 \mathrm{~g} \mathrm{~kg}^{-1}$ de massa seca.

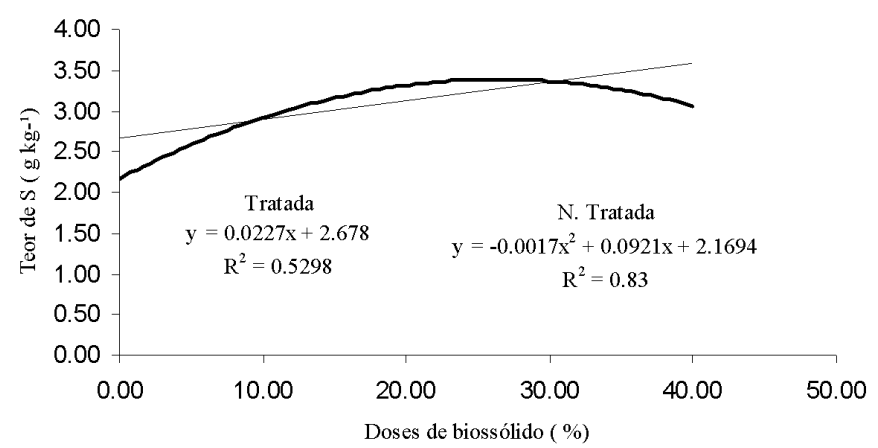

Figura 2. Teor de enxofre (S) em folhas de pinhãomanso em função de doses de biossólido após 60 dias de semeadura
Os teores de fósforo, cálcio e magnésio foram influenciados significativamente $(\mathrm{P} \leq 0,01)$ em função das doses de biossólido (Tabela 3) com redução desses nutrientes da ordem de 42,8, 37,9 e 50,1\% respectivamente, quando da participação do biossólido na composição de $40 \%$ do substrato. A adição de $20 \%$ de lodo de esgoto ao substrato reduziu o teor de P foliar para 2,48 $\mathrm{g} \mathrm{kg}^{-1}$, abaixo dos valores de referência da CFSEMG (1999) para a mamoneira, pertencente à mesma espécie uma vez que ainda não há valores estabelecidos para o pinhão-manso. Na Figura 3 nota-se, em relação à testemunha, que os teores de fósforo diminuem nas folhas à medida em que se aumenta a dose de biossólido $\left(\mathrm{R}^{2}=0,964\right)$. Em eucalipto Silva et al. (2008) observaram aumento da concentração dos elementos $\mathrm{P}, \mathrm{Ca} \mathrm{e}$ $\mathrm{Zn}$ nas folhas com as maiores doses dos biossólido; entretanto, com efeito inverso de $\mathrm{Mn}$, atribuído ao aumento do $\mathrm{pH}$ do solo.

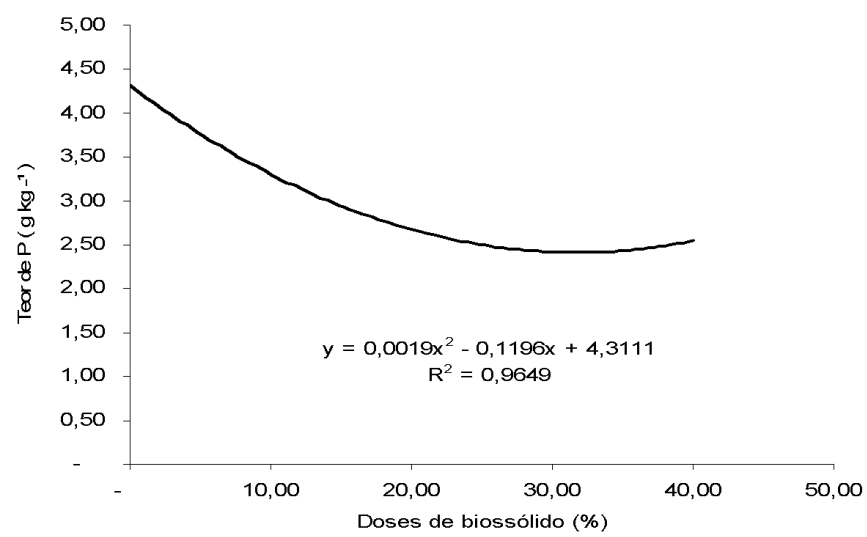

Figura 3. Teor de $\mathrm{P}$ em folhas de pinhão-manso em função de doses de biossólido aos 60 dias após a semeadura

Assim como para o P observa-se, na Figura 4, que os teores foliares de Ca também foram afetados negativamente. Segundo Kerbauy (2008) sua demanda pelas plantas para um crescimento ótimo corresponde à faixa de 10 a $50 \mathrm{~g} \mathrm{~kg}^{-1}$ de matéria seca e tem funções de elemento estrutural, regulatório e estimula diversas enzimas e proteínas que acionam os processos de defesa da planta. Para a mamona e segundo a CFSEMG (1999) os valores ideais estariam entre 15 e $25 \mathrm{~g} \mathrm{~kg}^{-1}$ acima, portanto dos valores observados para todos os tratamentos.

Avaliando o efeito de doses de lodo de esgoto na nutrição de Brachiaria decumbens, Araújo et al. (2009) observaran que nos tratamentos com lodo de esgoto os teores de fósforo aumentaram gradativamente mas, mesmo na maior dose de lodo, o teor foliar de $\mathrm{P}$ não diferiu significativamente do controle. Este resultado sugere que o lodo de esgoto, embora 
tenha contribuído para o aumento dos teores deste nutriente na planta, também promoveu aumento na produção da matéria seca, o que pode ter provocado o efeito de diluição deste nutriente. Em contrapartida, Chueiri et al. (2007) relataram, combinando doses de $0,25,50,75$ e $100 \%$ da adubação mineral recomendada para a cultura do trigo, com $0,2,5,5,0,7,5$ e 10,0 $\mathrm{Mg} \mathrm{ha}^{-1}$ do lodo de esgoto alcalinizado em base seca, que os teores de $\mathrm{K}, \mathrm{N}, \mathrm{Mg}, \mathrm{Cu}$ e $\mathrm{Zn}$ no tecido vegetal do trigo foram aumentados pelo lodo enquanto o fertilizante mineral os reduziu indicando o efeito de concentração e diluição, respectivamente. $\mathrm{Na}$ literatura se encontram resultados conflitantes quanto à dinâmica de acumulação de nutrientes em tecidos de plantas em função da aplicação de lodo de esgoto; todavia, há de se considerar a possibilidade do efeito de muitos fatores como a composição química do lodo, o período entre a aplicação no solo e as coletas de tecidos para análises, as características da espécie vegetal estudada e as possíveis interações com outros fatores de estudo.

Salienta-se que, mesmo na ausência do biossólido, a testemunha apresenta um valor de 4,32 $\mathrm{g} \mathrm{kg}^{-1}$, o qual se encontra na faixa da demanda de $\mathrm{P}$ pelas plantas para um crescimento ótimo devido, provavelmente, à adição de $5 \mathrm{~kg}$ $\mathrm{m}^{-3}$ de superfosfato simples em todos os tratamentos. Segundo Raij (1991) o fósforo é usado na formação de proteínas que participam nos processos metabólicos, junto com as enzimas, exercendo grande função estrutural e promovendo elevado crescimento vegetativo no estádio inicial de seus ciclos. Avaliando o efeito da adubação de plantio de mudas de pinhãomanso com doses de lodo de esgoto até 19,2 $\mathrm{t} \mathrm{ha}^{-1}$, Prates et al. (2011) relatam que na análise aos 18 meses após o plantio a campo foram encontrados incrementos nos teores em tecido foliar, exatamente para $\mathrm{P}, \mathrm{Ca}$ e $\mathrm{Mg}$; entretanto, Backes et al. (2009) não obtiveram elevação nos teores de $\mathrm{P}$ e Ca em mamoneira, aos 50 dias após a emergência quando da adição de até $32 \mathrm{t} \mathrm{ha}^{-1}$.

Observou-se elevação dos teores de micronutrientes foliares em função da adição do biossólido ao substrato (Tabela 4) em resposta à presença de alguns desses elementos em altas concentrações no biossólido puro (Tabela 1).

Tabela 4. Valores médios para micronutrientes nas folhas de pinhão-manso em função das doses de biossólido

\begin{tabular}{crrrrr}
\hline Doses de & \multicolumn{5}{c}{ Micronutrientes $\left(\mathbf{m g ~ k g}^{-1}\right)$} \\
biossólido (\%) & B & \multicolumn{1}{c}{ Cu } & Fe & \multicolumn{1}{c}{ Mn } & Zn \\
0 & 21,83 & 6,83 & 180,20 & 79,20 & 21,83 \\
10 & 27,33 & 8,50 & 217,00 & 99,33 & 40,33 \\
20 & 28,33 & 10,66 & 193,66 & 109,50 & 56,83 \\
30 & 35,33 & 10,83 & 186,66 & 116,45 & 72,66 \\
40 & 46,66 & 13,66 & 304,83 & 115,00 & 83,20 \\
\hline Media & 32,00 & 10,10 & 216,50 & 104,11 & 54,97 \\
\hline
\end{tabular}

Na Tabela 4 nota-se que principalmente Zn, Fe e B tiveram valores muito superiores aos obtidos por Laviola \& Dias (2008) para o pinhão-manso, respectivamente de 22,70, 150,5 e 29,2 $\mathrm{mg} \mathrm{kg}{ }^{-1}$.

Na Figura 5 pode-se observar redução acentuada nos teores foliares de magnésio com o aumento da concentração de biossólido no substrato. No tratamento com maior concentração

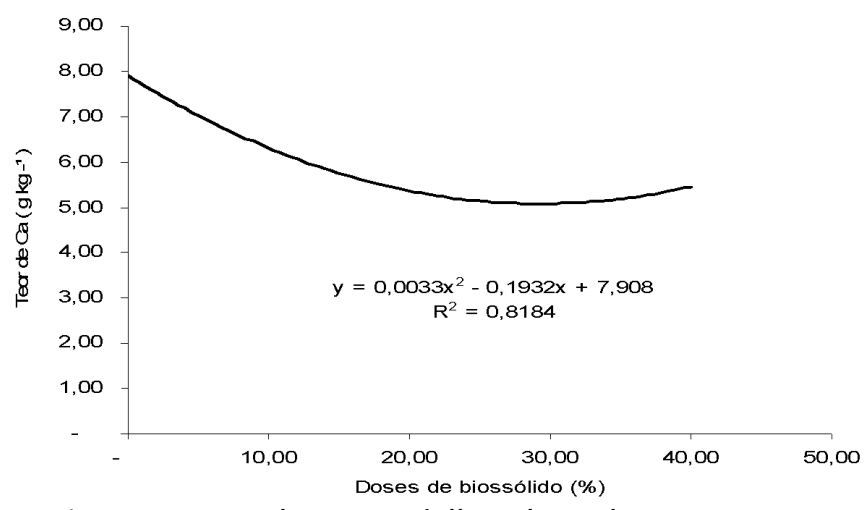

Figura 4. Teor de Ca em folhas de pinhão-manso em função de doses de biossólido aos 60 dias após a semeadura

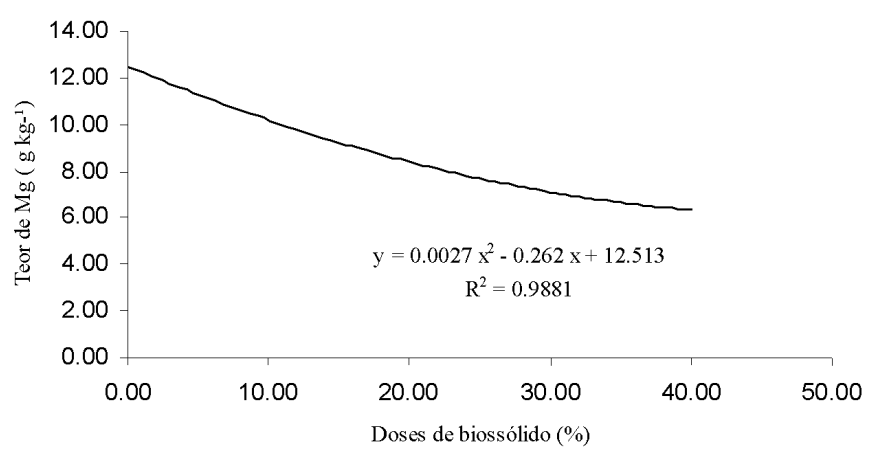

Figura 5. Teor de magnésio em folhas de pinhãomanso em função de doses de biossólido aos 60 dias após a semeadura

de biossólido o teor foi de $6,25 \mathrm{~g} \mathrm{~kg}^{-1}$, correspondendo à metade da testemunha $\left(12,52 \mathrm{~g} \mathrm{~kg}^{-1}\right)$; todavia, acima de $4,8 \mathrm{~g} \mathrm{~kg}^{-1}$ citado por Laviola \& Dias (2008) valor observado para uma lavoura instalada no campo, sem aplicação de lodo de esgoto.

Garcia et al. (2009) avaliaram mudas de eucalipto após aplicação de lodo de esgoto em recipientes de $50 \mathrm{~L}(0,25,50$, 75 e $\left.100 \mathrm{t} \mathrm{ha}^{-1}\right)$ e observaram aumentos dos teores foliares de N, P, K, Zn e Cu mas com diminuição de $\mathrm{Mg}, \mathrm{B}$ e Fe.

Na Tabela 4 verifica-se o acúmulo de micronutrientes, na seguinte ordem: $\mathrm{Fe}>\mathrm{Mn}>\mathrm{Zn}>\mathrm{B}>\mathrm{Cu}$. Comparando com os resultados obtidos por Laviola \& Dias (2008) que apresentaram a seguinte ordem: $\mathrm{Mn}>\mathrm{Fe}>\mathrm{B}>\mathrm{Zn}>\mathrm{Cu}$, observa-se que há uma inversão na posição para o Fe e Mn e entre Zn e B enquanto o $\mathrm{Cu}$ foi o menos absorvido em ambos os ensaios.

A Tabela 5 apresenta o resumo da análise de variância para os valores médios referentes aos micronutrientes retidos nas folhas das plantas de pinhão-manso. Verifica- se que o efeito das doses de biossólido foi significativo para os micronutrientes $\mathrm{B}, \mathrm{Cu}, \mathrm{Mn}$ e $\mathrm{Zn}$. Houve interação significativa entre os fatores doses de biossólido e tratamento das sementes para o elemento Mn enquanto para o tratamento de sementes o efeito foi significativo apenas para o micronutriente $\mathrm{Zn}$.

Conforme Kerbauy (2008) os efeitos adicionais produzidos pela matéria orgânica são decorrentes do aumento da solubilidade de complexos orgânicos formados sobretudo com micronutrientes. O boro é essencial na germinação dos grãos de pólen para o crescimento do tubo polínico enquanto para a 
Tabela 5. Resumo da análise de variância para teores de micronutrientes ( $\mathrm{mg} \mathrm{kg}^{-1}$ de massa seca) em folhas de pinhão-manso em função de diferentes doses de biossólido ( D) e tratamento de sementes (T)

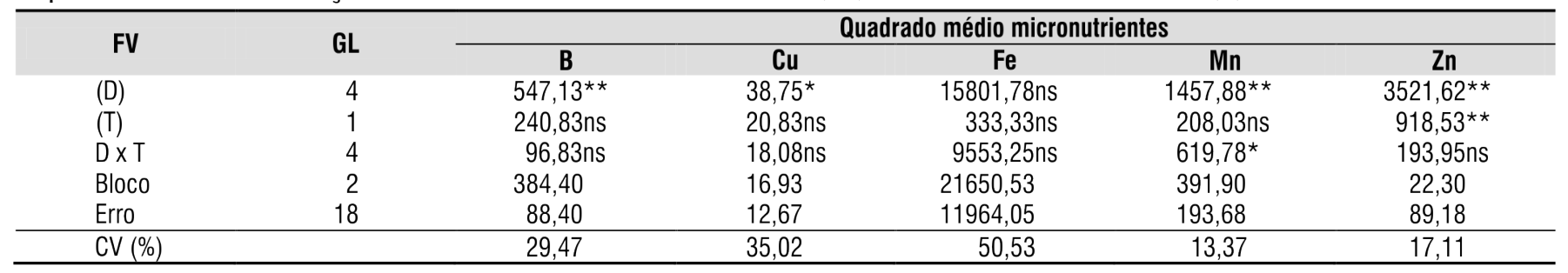

ns não significativo ao nível de 0,05 ; * Significativo a nível de 0,05 pelo teste $\mathrm{F}$; ${ }^{*}$ Significativo a nível de 0,01 pelo teste $\mathrm{F}$

formação das sementes é importante na formação das proteínas; na faixa de $\mathrm{pH}$ dos solos cultivados o boro ocorre na solução do solo na forma de ácido bórico $\left(\mathrm{H}_{3} \mathrm{BO}_{3}\right)$; é, portanto, o único nutriente que ocorre na solução, na forma neutra.

Por esta razão é um micronutriente muito susceptível a perdas por lixiviação (Furtini Neto et al., 2001). Na Figura 6 observa-se que o teor de boro (B) aumenta com as doses de biossólido sendo que, para cada $1 \%$ de aumento de biossólido, há uma elevação de $0,58 \mathrm{mg} \mathrm{kg}^{-1}$ de boro nas folhas de pinhãomanso. O boro é o micronutriente que está em menor quantidade no biossólido; todavia, a adição de $20 \%$ de biossólido elevou o teor de B de 21,83 para 28,33, muito próximo do nível descrito por Laviola \& Dias (2008).

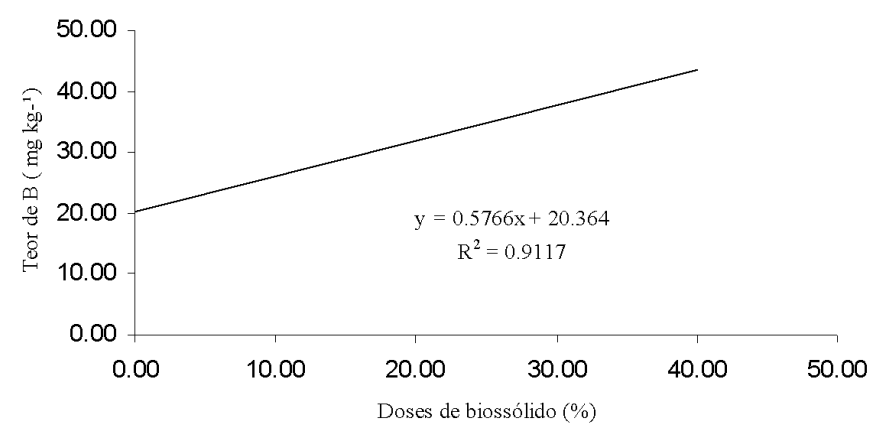

Figura 6. Teor de boro (B) em folhas de pinhão-manso em função das doses de biossólido aos 60 dias após a semeadura

O cobre é importante para a formação da clorofila e realização da fotossíntese nas plantas. Na Figura 7 observase, para cada $1 \%$ de aumento na dose de biossólido, que o teor de cobre se eleva em $0,16 \mathrm{mg} \mathrm{kg}^{-1}\left(\mathrm{R}^{2}=0,95\right)$. Segundo Luchese et al. (2001) o cobre é o micronutriente que, com a matéria orgânica, forma complexos mais estáveis. No caso do biossólido utilizado (Tabela 1) verifica-se que o teor de cobre é alto $\left(1552 \mathrm{mg} \mathrm{kg}^{-1}\right)$.

Segundo Kirkby \& Romheld (2007) a mobilidade do Cu nas plantas é limitada e depende do estado nutricional em termos de $\mathrm{Cu}$ e N. Um alto suprimento de $\mathrm{N}$ diminui a disponibilidade de $\mathrm{Cu}$ dentro das plantas tendo, como necessário, uma dosagem maior de $\mathrm{Cu}$ para aumentar a produtividade.

Na Tabela 6 observa-se que com 30\% de biossólido no substrato o teor de manganês nas sementes tratadas se diferenciou significativamente em relação às não tratadas. $\mathrm{O}$ máximo acúmulo de $\mathrm{Mn}\left(125,40 \mathrm{mg} \mathrm{kg}^{-1}\right)$ para as sementes tratadas acontece com $31 \%$ de biossólido (Figura 8). Em mudas de eucalipto, entretanto, Garcia et al. (2009) relatam que o teor

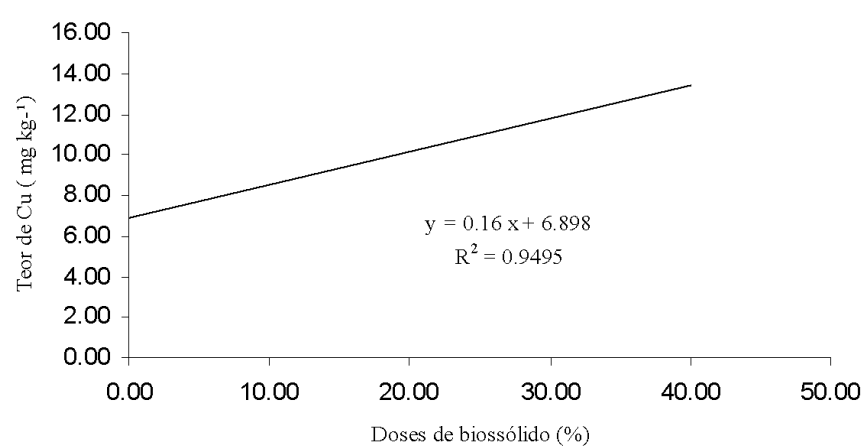

Figura 7. Teor de cobre $(\mathrm{Cu})$ em folhas de pinhãomanso em função de doses de biossólido aos 60 dias após a semeadura

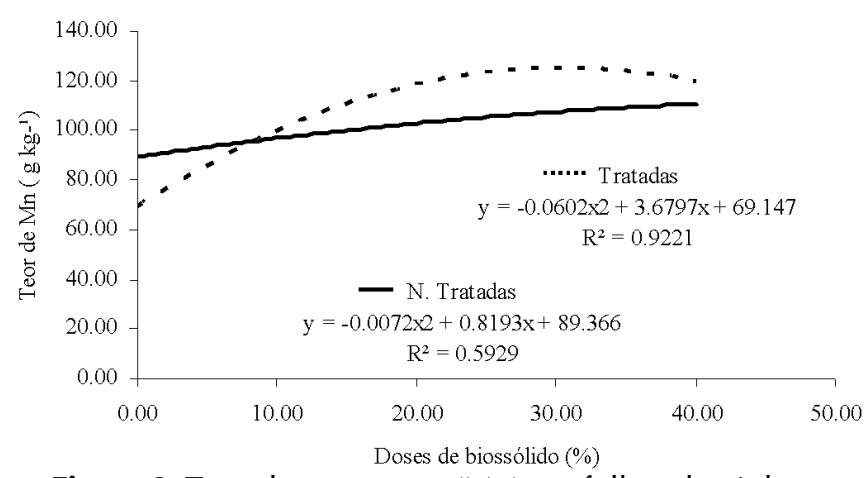

Figura 8. Teor de manganês (Mn) em folhas de pinhãomanso em função de doses de biossólido aos 60 dias de semeadura

foliar de Mn permaneceu inalterado com a aplicação de doses de lodo de esgoto de até $100 \mathrm{t} \mathrm{ha}^{-1}$.

A principal forma de manganês na solução do solo e também na qual é absorvido pelas plantas, é o $\mathrm{Mn}^{2+}$. Segundo Furtini Neto et al. (2001) sua concentração na solução do solo, à semelhança do ferro, também depende de reações de oxiredução, de forma que sua disponibilidade depende do teor de matéria orgânica, da atividade microbiana e da umidade do solo.

O manganês interfere na absorção, no transporte e no uso de vários nutrientes essenciais, como $\mathrm{Ca}, \mathrm{Mg}, \mathrm{K}, \mathrm{P}$ e N (Mukhopadhyay \& Sharma, 1991) mas principalmente de $\mathrm{Cu}$, $\mathrm{Zn}$ e Fe.

Pode-se observar, na Tabela 7, um teor maior de $\mathrm{Zn}$ nas folhas de pinhão-manso na medida em que há aumento das doses de biossólido nas sementes tratadas em comparação com as não tratadas (Figura 9). Considerando que o zinco não é componente do 1-(4-chlorobenzyl)-1-cyclopentyl-3-phenylurea (Pecicuron), princípio ativo do Monceren, acredita-se que o 
Tabela 6. Teores de manganês (Mn) em $\mathrm{mg} \mathrm{kg}^{-1}$ de massa seca em folhas de pinhão-manso, 60 dias após a semeadura em função de diferentes doses de biossólido ( D) e tratamento de sementes (T)

\begin{tabular}{lcccccc}
\hline \multirow{2}{*}{ Semente } & \multicolumn{5}{c}{ Porcentagem de biossólido no substrato } \\
\cline { 2 - 4 } & $\mathbf{0}$ & $\mathbf{1 0}$ & $\mathbf{2 0}$ & $\mathbf{3 0}$ & $\mathbf{4 0}$ & Média \\
Tratadas & $73,66 \mathrm{a}$ & $90,00 \mathrm{a}$ & $121,33 \mathrm{a}$ & $131,66 \mathrm{a}$ & $116,33 \mathrm{a}$ & $106,73 \mathrm{a}$ \\
Não tratadas & $84,66 \mathrm{a}$ & $108,00 \mathrm{a}$ & $97,66 \mathrm{a}$ & $103,33 \mathrm{~b}$ & $113,66 \mathrm{a}$ & $101,46 \mathrm{a}$ \\
Média & 79,16 & 99,33 & 109,50 & 117,50 & 115,00 & \\
\hline CV $=13,37 \%$ & & \multicolumn{5}{c}{}
\end{tabular}

Média seguidas de letras distintas na coluna diferem entre si pelo teste de Tukey a $5 \%$ de probabilidade

Tabela 7. Teor de Zinco (Zn) em $\mathrm{mg} \mathrm{kg}^{-1}$ de massa seca em folhas de pinhão-manso 60 dias após a semeadura em função de diferentes doses de biossólido e tratamento de sementes

\begin{tabular}{|c|c|c|c|c|c|c|}
\hline \multirow{2}{*}{ Semente } & \multicolumn{6}{|c|}{ Porcentagem de biossólido no substrato (\%) } \\
\hline & 0 & 10 & 20 & 30 & 40 & Média \\
\hline Não tratadas & $23,66 \mathrm{a}$ & $40,66 \mathrm{a}$ & $46,66 \mathrm{~b}$ & $65,33 \mathrm{a}$ & $72,00 \mathrm{~b}$ & $49,66 b$ \\
\hline
\end{tabular}

Médias seguidas por letras distintas na coluna diferem entre si pelo teste de Tukey a 0,05 de probabilidade

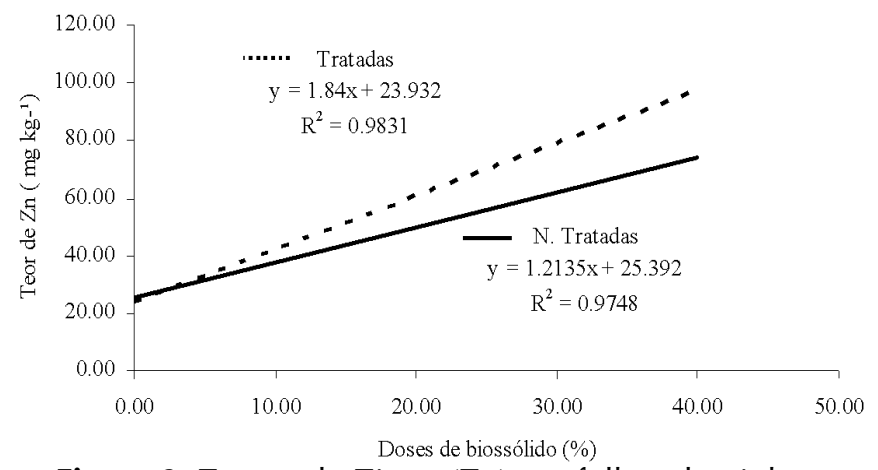

Figura 9. Teores de Zinco (Zn) em folhas de pinhãomanso em função de doses de biossólido aos 60 dias de semeadura

resultado seja um efeito indireto do tratamento das sementes, merecendo maiores estudos.

$\mathrm{O}$ zinco é absorvido pelas plantas na forma catiônica $\mathrm{Zn}^{2+}$ e auxilia no crescimento e nos sistemas enzimáticos, além de essencial para a produção da clorofila e carboidratos. Na Figura 9 mostra-se que para cada $1 \%$ de aumento da dose de biossólido no substrato o teor de zinco aumenta de $1,84 \mathrm{mg} \mathrm{kg}^{-1}$ nas folhas de pinhão-manso para as sementes tratadas.

A demanda de $\mathrm{Zn}$ pelas plantas está na faixa de 15 a 30 $\mathrm{mg} \mathrm{kg}^{-1}$ de matéria seca de folhas e pode ser maior quando ocorre alta concentração de $\mathrm{P}$ no tecido (Kerbauy, 2008). Aumentos nos teores de $\mathrm{Zn}$ em plantas fertilizadas com lodo de esgoto foram também descritos por outros autores (Anjos \& Mattiazo, 2000; Backes et al., 2009; Garcia et al., 2009).

Outro fator a ser considerado neste trabalho refere-se às características físicas do substrato que podem ter interferido nos resultados obtidos. O diâmetro médio de Sauter das partículas do biossólido utilizado foi de 0,0936 mm (Maldonado, 2004) sendo esta uma granulometria muito fina, assim como da vermiculita. Portanto, pode-se inferir que, quanto maior sua concentração na composição do substrato, menor a macroporosidade do mesmo e, consequentemente, menor a capacidade de trocas gasosas. De acordo com Oliveira et al. (2005) o processo de germinação é alterado por fatores como a umidade, temperatura, luz, oxigênio e o substrato; logo, se existe deficiência de oxigênio, os processos de germinação e emergência são prejudicados. Trigueiro \& Guerrini (2003) observaram, testando substratos para produção de mudas de eucalipto, que o substrato que continha a proporção de $80 \%$ de biossólido para $20 \%$ de casca de arroz carbonizada foi extremamente prejudicial à germinação e sobrevivência das plantas de eucalipto devido às características deste substrato que conferiu baixa quantidade de macroporos e alta densidade aparente. Camargo et al. (2010) concluíram, estudando a formação de mudas de pinhão-manso com substrato contendo biossólido, que doses de biossólido acima de $10 \%$ resultaram em prejuízos no desenvolvimento das plantas indicando que podem existir limitações químicas e/ou físicas para uso deste resíduo na formação de mudas em tubetes.

\section{Conclusões}

1. As folhas de pinhão-manso apresentaram um acúmulo de macronutrientes de acordo com a seguinte ordem: $\mathrm{N}>\mathrm{K}>$ $\mathrm{Mg}>\mathrm{Ca}>\mathrm{P}>\mathrm{S}$.

2. $\mathrm{O}$ acúmulo de micronutrientes nas folhas de pinhãomanso obedeceu à seguinte ordem: $\mathrm{Fe}>\mathrm{Mn}>\mathrm{Zn}>\mathrm{B}>\mathrm{Cu}$.

3. Há uma grande contribuição do biossólido nos teores de nitrogênio, enxofre e micronutrientes foliares, em plantas de pinhão-manso.

\section{AgradeCIMENTOS}

Ao Instituto de Ciências Agrárias da UFU e à FAPEMIG.

\section{Literatura Citada}

Anjos, A. R. M.; Mattiazo, M. E. Metais pesados em plantas de milho cultivadas em latossolos repetidamente tratados com biossólido. Scientia Agrícola, v.57, p.769776, 2000.

Araújo, F. F.; Gil, F. C.; Tiritan, C. S. Lodo de esgoto na fertilidade do solo, na nutrição de Brachiaria decumbens e na atividade da desidrogenase. Pesquisa Agropecuária Tropical, v.39, p.1-6, 2009. 
Arruda, F. P.; Beltrão, N. E. de M.; Andrade, A. P.; Pereira, W. E.; Severino, L. S. Cultivo de pinhão- manso (Jatropha curcas L.) como alternativa para o semi-árido nordestino. Revista Brasileira de Oleaginosas e Fibrosas, v.8, p.789799, 2004.

Backes, C.; Lima, C. P.; Fernandes, D. M.; Godoy, L. J. G.; Kiihl, T. A. M.; Villas Bôas, R.L. Efeito do lodo de esgoto e nitrogênio na nutrição e desenvolvimento inicial da mamoneira. Bioscience Jounal, v.25, p.90-98, 2009.

Camargo, R de. ; Maldonado, A. C. D. ; Silva, P. A.; Costa, T. R. da; Biossólido como substrato na produção de mudas de pinhão-manso. Revista Brasileira de Engenharia Agrícola e Ambiental v.14, p.1304-1310, 2010.

Campos, F. da S.; Alves, M. C. Uso de lodo de esgoto na reestruturação de solo degradado. Revista Brasileira de Ciência do Solo, v.32, p.1389-1397, 2008.

CFSEMG - Comissão de Fertilidade do Solo do Estado de Minas Gerais. Recomendações para o uso de corretivos e fertilizantes em Minas Gerais, $5^{\text {a }}$ aproximação. Lavras: UFLA, 1999. 359p.

Chueiri, W.; Serrat, B. M.; Biele, J.; Favaretto, N. Lodo de esgoto e fertilizante mineral sobre parâmetros do solo e de plantas de trigo. Revista Brasileira de Engenharia Agrícola e Ambiental, v.11, p.502-508, 2007.

Colodro, G.; Espíndola, C. R. Alterações na fertilidade de um latossolo degradado em resposta à aplicação de lodo de esgoto. Acta Scientiarum Agronomy, v.28, p.1-15, 2006.

CONAMA - Conselho Nacional do Meio Ambiente. Resolução n. 375/2006. Ministério do Meio Ambiente. Define critérios e procedimentos para o uso agrícola de lodos de esgoto gerados em estações de tratamento de esgoto sanitário e seus produtos derivados. Diário Oficial da República Federativa do Brasil, Brasília, n.167, p.141-146, 2006.

Faustino, R.; Kato, M. T.; Florêncio, L.; Gavazza. S. Lodo de esgoto como substrato para produção de mudas de Senna siamea Lam. Revista Brasileira de Engenharia Agrícola e Ambiental, v 9, p.278-282, 2005.

Fernández, S.; Vidal, D.; Simón, E.; Sugrañes, L. Radiometric characteristics of Triticum aestivum cv. Astral under water and nitrogen stress. International Journal of Remote Sensing, v.15 p.1867- 884, 1994.

Furtini Neto, A. E.; Vale, F. R.; Resende, A.V.; Guilherme, L. R. G.; Guedes, G.A.A. Fertilidade do solo. Lavras: UFLA, 2001. 252p.

Garcia, G. O.; Gonçalves, I. Z.; Madalão, J. C.; Nazário, A. A.; Reis, E. F. Análise nutricional de mudas de eucalipto submetidas à aplicação de lodo de esgoto doméstico. Engenharia Ambiental, v.6, p.275-290, 2009.

Gomes, S. B. V.; Nascimento, C. W. A.; Biondi, C. M. Produtividade e composição mineral de plantas de milho em solo adubado com lodo de esgoto. Revista Brasileira de Engenharia Agricola e Ambiental, v.11, p.459-465, 2007.

Kerbauy, G. B. Fisiologia vegetal. 2.ed. Rio de Janeiro: Guanabara Koogan, 2008. 431p.
Kirkby, E. A. ; Romheld, V. Micronutrientes na fisiologia de plantas: Função, absorção e mobilidade . Piracicaba: IPNI, 2007. 24p. Encarte técnico 118

Laviola, B. G.; Dias, L. A.dos S. Teor e acúmulo de nutrientes em folhas e frutos de pinhão-manso. Revista Brasileira de Ciência do Solo, v.32, p.1969-1975, 2008.

Lima, R. L.; Severino, L. S.; Ferreira, G. B.; Sofiatti, V.; Sampaio, L. R.; Beltrão, N. E. de M. Casca de mamona associada a quatro fontes de matéria orgânica para a produção de mudas de pinhão-manso. Revista Ceres, v.58, p.232-237, $2011 \mathrm{a}$.

Lima, R. L. S.; Severiano, L. S.; Cazetta, J. O.; Azevedo, C. A. V.; Sofiatti, V.; Arriel, N.H.C. Posição da folha e estádio fenológico do ramo para análise foliar do pinhão-manso. Revista Brasileira de Engenharia Agrícola e Ambiental, v.15, p.1068-1072, 2011b.

Luchese, E. B. ; Favero, L. O. B. ; Lenzi, E.. Fundamentos da química do solo, teoria e prática. 1.ed. Rio de Janeiro: Freitas Bastos, 2001. 157p.

Maldonado, A. C. D. Secagem de lodo de reator anaeróbio em secador rotativo com recheio de inertes. Uberlândia: UFU, 2004. 13p. Dissertação Mestrado

Melo, V. P.; Beutler, A. N.; Souza, Z. M.; Centurion, J. F.; Melo, W. J. Atributos físicos de Latossolos adubados durante 5 anos com biossólido. Pesquisa Agropecuária Brasileira, v.39, p.67-72, 2004.

Mukhopadhyay, M. J.; Sharma, A. Manganese in cell metabolism of higher plants. The Botanical Review, v.57, p.117-149, 1991.

Oliveira, I. V. M.; Cavalcante, I. H. L.; Beckmann, M. Z.; Martins, A. B. G. Temperatura na germinação de sementes de Sapota Preta. Revista de Biologia e Ciências da Terra, v.5, p.1-7, 2005.

Prates, F. B. S.; Sampaio, R. A.; Silva, W. J.; Fernandes, L. A.; Zuba Junio, G. R.; Saturnino, H. M. Crescimento e teores de macronutrientes em pinhão manso adubado com lodo de esgoto e silicato de cálcio e magnésio. Revista Caatinga, v.4, p.101-112, 2011.

Raij, B. van. Fertilidade do solo e adubação. São Paulo: Agronômica Ceres, 1991. 343p.

Saturnino, H. M.; Pacheco, D. D.; Kakida, J.; Tominaga, N.; Gonçalves, N. P. Cultura do pinhão-manso (Jatropha curcas L.). Informe agropecuário, v.26, p.44-78, 2005.

Silva, P. H.; Poggiani, F.; Gonçalves, J. L. M.; Stape, J. L. Volume de madeira e concentração foliar de nutrientes em parcelas experimentais de Eucalyptus grandis fertilizadas com lodos de esgoto úmido e seco. Revista Árvore, v.32, p.845-854, 2008.

Trannin, I. C. de B.; Siqueira, J. O.; Moreira, F. M de S. Avaliação agronômica de um biossólido industrial para cultura do milho. Pesquisa Agropecuária Brasileira, v.40, p.261-269, 2005.

Trigueiro, R. M.; Guerrini, I. A. Uso de biossólidos como substrato para produção de mudas de eucalipto. Revista Scientia Forestalis, n.64, p.150-162, 2003. 